\title{
Catalytic reforming of gaseous products from pyrolysis of low-density polyethylene over iron-modified ZSM-5 catalysts
}

\author{
Abubakar Y. Waziri ${ }^{1}$ - Aisha A. Osigbesan ${ }^{1} \cdot$ Fadimatu N. Dabai ${ }^{1} \cdot$ Suleiman M. Shuwa ${ }^{1} \cdot$ Abdulazeez Y. Atta $^{1}$ (1) \\ Baba Y. Jibril ${ }^{1}$
}

Received: 13 January 2019 / Accepted: 10 June 2019 / Published online: 20 June 2019

(c) The Author(s) 2019

\begin{abstract}
Converting plastic wastes into fuels through catalytic cracking is continuously gaining interest from researchers worldwide. In this study, the influence of iron on ZSM-5 (Fe-ZSM-5) catalyst on the reforming of the gaseous products of thermal decomposition of low-density polyethylene (LDPE) was investigated. The acidified ZSM-5 catalysts (0, 0.3, 0.6 and $1 \mathrm{wt} \%$ of Fe) were prepared and characterized by XRD, BET, FTIR and SEM techniques. In particular, the effects of temperature (400, 450 and $\left.500{ }^{\circ} \mathrm{C}\right)$ and catalyst loading $(0.5,0.75,1.0,1.25$ and $1.5 \mathrm{~g})$ on a two-stage (pyrolyser and reformer) decomposition of the LDPE wastes into fuel were studied. The liquid fraction produced was characterized using FTIR and GC/MS techniques. The study showed that the increase in pyrolysis temperature $\left(400-500{ }^{\circ} \mathrm{C}\right)$ increases the volume of non-condensable gas $(31-58 \mathrm{wt} \%)$ and decreases the volume of the condensates $(69-41 \mathrm{wt} \%)$ in both the thermal and catalytic pyrolyses. However, the trend was at higher level for the catalytic pyrolysis. The increase in temperature for the thermal pyrolysis had less significant effect on the aromatization content of the liquid condensate compared to the catalytic pyrolysis. The FTIR results show a significant increase in aromatic contents and decrease in the aliphatic of the liquid fraction for the catalytic pyrolysis reforming when compared with thermal pyrolysis. The GC/MS results confirmed the aromatic hydrocarbon compositions, predominantly p-xylene, increased relatively to about $70 \%$ in the liquid fraction for the best catalyst $\left(1.25 \mathrm{~g}\right.$ of catalyst and $1 \mathrm{wt} \%$ iron loading on ZSM-5 at $\left.450{ }^{\circ} \mathrm{C}\right)$.
\end{abstract}

Keywords Aromatic $\cdot$ Catalytic cracking $\cdot$ Fe-ZSM-5 $\cdot$ Low-density polyethylene (LDPE)

\section{Introduction}

Plastics have revolutionized the quality of life, and increasingly, many new life-saving devices are being made from them. They are indispensables nowadays because of their versatility and low cost [1]. However, enormous volumes of plastics composed of bags, dishes, packing materials, etc., after daily use, generate tons of wastes [2]. Plastics have unique properties because of their strong chemical bonds, which make them adequate for many applications. However, these bonds are not biodegradable. Thus, plastic wastes quickly become pollutant to the environment (air, land and water), exhaust the landfills, produce hazardous pollutant during incineration and endanger wild and civil life [3]. These plastic wastes have been suggested could be

Abdulazeez Y. Atta

zeezoatta@gmail.com; ayatta@abu.edu.ng

1 Department of Chemical Engineering, Ahmadu Bello University, Zaria, Nigeria recovered by thermal or catalytic decomposition into chemicals and energy $[2,4]$.

It is predicted that petroleum resources are decreasing, while demands for petrochemicals are increasing for both industrial uses and energy production [5]. The demand for energy is increasing globally due to the rapid growth of population, urbanization and industrial development. The socioenvironmental concerns associated with conventional fossil fuels, such as elevating fuel prices, pollution and global warming, are encouraging a move towards renewable resources [4]. Therefore, it is important to provide an alternative to petroleum resources. The conversion of plastic wastes to chemicals and energy is expected to provide a viable alternative. Thus, the conversion of plastic wastes from municipal solid wastes (MSW) to fuel through pyrolysis of long-chain to short-chain hydrocarbon fragments has several benefits. First, it steps up a new cycle of consumption to non-renewable energy sources. Secondly, it also provides a considerable source of petrochemicals that reduces the expenditure of non-renewable energy resources. Thirdly, it establishes an effective, innovative and

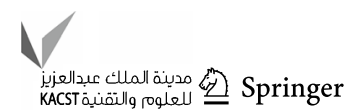


alternative solution for eliminating plastic waste, consequently preventing them from polluting the environment through either incineration or filling up landfills and waterways $[6,7]$.

The process of waste conversion to fuel can be aided by a catalyst [8]. Catalytic degradation of polymers that employed various zeolite and non-zeolite-type catalysts has been reviewed in the literature [9]. It has been reported [10] that zeolite-type catalyst in the degradation process of plastics has shown a positive effect on the quality of products obtained. Among zeolite-type catalysts, H-ZSM-5 reportedly yields more gas fraction and aromatic hydrocarbons in the catalytic degradation of polyethylene [11]. Also this catalyst increases the ratio of branched hydrocarbon to normal hydrocarbon and decreases the formation of straight-chain paraffins and olefins [9]. Most literatures on thermal and catalytic degradation of plastics are concerned with the product yields, such that the catalytic efficiency of cracking, aromatization and isomerization has not been given much attention. It is suggested that precise hydrocarbon composition of oil products will make it possible to understand the catalytic efficiency and predict the oil quality [10].

Gallium and other transition metals are added to the ZSM-5 catalysts to improve the aromatic content of liquid fuel in thermo-catalytic pyrolysis of plastics. In catalytic degradation of plastic waste (polyolefin) using Ga-ZSM-5 in a pilot plant $(10 \mathrm{~kg} / \mathrm{h})$, more than $80 \%$ of the liquid fuel comprised of aromatic compounds, of which $90 \%$ was BTX (benzene, toluene, o-xylene, m-xylene and p-xylene) [12]. A two-stage catalytic degradation process of low-density polyethylene using ZSM-5 (loaded with iron) was carried out in this work. This approach is unlike some previous studies that utilized gallium-based catalyst. Gallium was substituted with iron in this study, because it belongs to the same transition metals, it is less expensive, and it has been used in similar works with satisfactory results. Also, iron showed a good performance in a two-stage pyrolysis-catalytic steam-reforming process, which used mesoporous MCM-41, supported with iron and nickel, for hydrogen-rich syngas production from a simulated mixture of waste plastics [13]. According to the study, $\mathrm{Fe}-\mathrm{Ni}$ MCM-41 produced a synergistic enhancement of the total gas yield and hydrogen and carbon monoxide production, and also showed the lowest carbon deposition on the catalyst. Thus, this study employed Fe-ZSM-5, for catalytic degradation of LDPE pyrolysis products, to ascertain the effect of the catalyst.

\section{Materials and method}

\section{Materials}

Low-density polyethylene was picked from commercial waste disposal, washed with water, dried in an oven $\left(\right.$ at $80^{\circ} \mathrm{C}$ ) and then cut to smaller sizes $(1-3 \mathrm{~cm})$ using scissors. The ZSM-5 zeolite $(\mathrm{Si} / \mathrm{Al}=50)$ and iron III nitrate nonahydrate were purchased from Zeolyst International and Sigma-Aldrich, respectively.

\section{Catalyst preparation}

Fe-ZSM-5 zeolite sample was prepared using ion exchange method following the procedure in the literature [14]. Commercial ZSM-5 (supplied from Zeolyst, with $\mathrm{Si} / \mathrm{Al}=50$ ) was dissolved in $500 \mathrm{ml}$ of distilled water. The resulting solution was then treated with $500 \mathrm{ml}$ of 1 molar solution of $\mathrm{HCl}$ under reflux condition at a pressure of $1 \mathrm{~atm}$ for $1 \mathrm{~h}$, to convert the catalyst into acidic form $\left(\mathrm{NH}_{4}-\mathrm{ZSM}-5\right)$. The sample was filtered, washed with distilled water, dried at $80{ }^{\circ} \mathrm{C}$ for $10 \mathrm{~h}$, crushed and then calcined in air for $3 \mathrm{~h}$ at $500{ }^{\circ} \mathrm{C}$ to activate the catalysts (H-ZSM-5). $20 \mathrm{~g}$ of the H-ZSM-5 and a required amount of precursor $\left(\mathrm{Fe}-\left(\mathrm{NO}_{3}\right)_{3} \cdot 9 \mathrm{H}_{2} \mathrm{O}\right)$ based on Eq. (1) were dissolved in $500 \mathrm{ml}$ and $100 \mathrm{ml}$ of distilled water, respectively. The two resulting solutions were mixed in a dropwise manner under the reflux condition at $1 \mathrm{~atm}$ for $3 \mathrm{~h}$ to have a uniform dispersion of the active site. The samples were dried at $80^{\circ} \mathrm{C}$ for $10 \mathrm{~h}$, crushed and then calcined in air for $3 \mathrm{~h}$ at $500{ }^{\circ} \mathrm{C}$. The samples were labelled A1, A2, A3, A4 and A5, for the commercial ZSM-5, acid-treated ZSM-5, $0.3 \mathrm{wt} \% \mathrm{Fe}_{2} \mathrm{O}_{3}$ on acid-treated ZSM-5, $0.6 \mathrm{wt} \% \mathrm{Fe}_{2} \mathrm{O}_{3}$ on acid-treated ZSM-5 and $1.0 \mathrm{wt} \% \mathrm{Fe}_{2} \mathrm{O}_{3}$ on acid-treated ZSM-5, respectively. The stated iron contents (for the catalysts) were mainly based on the amount added during synthesis.

$$
4 \mathrm{Fe}\left(\mathrm{NO}_{3}\right)_{3} 9 \mathrm{H}_{2} \mathrm{O} \rightarrow 2 \mathrm{Fe}_{2} \mathrm{O}_{3}+12 \mathrm{NO}_{2}+3 \mathrm{O}_{2}+36 \mathrm{H}_{2} \mathrm{O}
$$

\section{Catalysts characterization}

The catalysts were characterized using XRD, FTIR, BET and SEM techniques. The structures of ZSM-5 materials were studied with a Rigaku MiniFlex 600 X-ray diffractometric. The X-ray diffraction (XRD) patterns were recorded in air at room temperature using Rigaku MiniFlex $600 \mathrm{Cu} \mathrm{K} \alpha$ radiation source operating at $40 \mathrm{kV}$ and $15 \mathrm{~mA}$ in a scanning range of 10-90 $2 \theta$ at $0.02^{\circ}$. Using the wavelength $154 \mathrm{~A}^{\circ}$ and a speed of $10 \% \mathrm{~min}$, the diffraction data of the XRD crystallinity were determined. Based on the XRD results, the crystallite sizes of the catalysts were estimated using the Debye-Scherrer method.

$D=\frac{k \lambda}{\beta \cos \theta}$

From Eq. (2), $D$ represents the average size of the crystal, $k$ is the dimensionless shape factor, $\lambda$ is the $\mathrm{X}$-ray wavelength and $\beta$ is the full width at half maximum (FWHM) of selected peak at $2 \theta$ diffraction angle.

Fourier transform infrared (FTIR) analysis was performed with a Shimadzu (FTIR-8400S) spectrometer machine using potassium bromide $(\mathrm{KBr})$ pellets. The infrared spectra of 
these samples were measured in the transmission mode within the wavelength number range of 4000 and $500 \mathrm{~cm}^{-1}$.

The morphology of the catalyst, such as specific surface area, pore volume and pore size, were analysed by the Brunauer-Emmett-Teller (BET) method with $\mathrm{N}_{2}$ adsorption desorption isotherm at $77 \mathrm{~K}$, using APPI machine V-Sorb 2800P surface area analyser. The samples were degassed at $523 \mathrm{~K}$ for $16 \mathrm{~h}$ before the sorption measurements at a heating rate of $1{ }^{\circ} \mathrm{C} / \mathrm{min}$. The micropore area and micropore volume were calculated using the Langmuir surface area and t-plot method, respectively [15]. The micropore size distribution was calculated using the Horvath-Kawazoe (HK) method [16].

Scanning electron microscopy (SEM) images was taken using a Philips environmental scanning electron microscope FESEM (JOEL, JSM 6031) machine in high-vacuum mode (to prevent interference of pictures) at $20 \mathrm{kV}$, equipped with energy-dispersive spectroscopy. Before the images were captured, the foci, brightness, contrast and magnification were adjusted.

\section{Catalysts performance test}

The pyrolysis of low-density polyethylene experiment was carried out using a two-stage reactor (pyrolyser and reformer). Figure 1 shows a schematic diagram of the experimental set-up, which consists of pyrolyser (R1), fixed bed reactor (R2), condenser (E1), separating tank, nitrogen cylinder and controllers. The reformer, which is made of stainless steel and surrounded by heating element, has a length of $20.5 \mathrm{~cm}$ and diameter of $2 \mathrm{~cm}$. A (500-ml) threenecked round-bottle flask coupled with an external thermocouple and a nitrogen line immersed in a heating mantle at $5^{\circ} \mathrm{C} / \mathrm{min}$ heating rate served as the pyrolyser (R1).
In the first set of experiments, the temperature of the second stage (catalytic bed) was varied at 400, 450 and $500{ }^{\circ} \mathrm{C}$, while the catalyst loading was kept constant at $1 \mathrm{~g}$. In the second set of experiments, the catalyst loading was varied at $0.5,0.75,1,1.25$ and $1.5 \mathrm{~g}$, while the temperature was kept constant $\left(450^{\circ} \mathrm{C}\right)$. In each experimental run, the temperature of the pyrolyser (first stage), the residence time and the mass of the feed (LDPE) were kept constant at $400{ }^{\circ} \mathrm{C}, 25 \mathrm{~min}$ and $10 \mathrm{~g}$, respectively. Glass wool was used before and after the catalyst to minimize gas phase reaction. The catalyst was mixed with a glass beat.

Prior to the reaction, the system was scrubbed with nitrogen gas flowing at $200 \mathrm{ml} / \mathrm{min}, 1.5 \mathrm{bar}$ and $25^{\circ} \mathrm{C}$ for 30 min to create an inert environment. The temperature of the reformer was allowed to rise to the desired temperatures, at the heating rate of $0.45{ }^{\circ} \mathrm{C} / \mathrm{s}$, before the pyrolyser was switched on at the heating rate of $0.5^{\circ} \mathrm{C} / \mathrm{s}$. The gaseous products of the pyrolyser were allowed to pass through the fixed catalyst bed where they came into contact with catalyst and the reforming took place. The products flowed from the reformer into a condenser, where the condensate and gas were separated using a circulating chiller. All the experimental runs were repeated three times, and high reproducibility was observed in the result.

The liquid products were collected and weighed using an electronic balance, before further analyses were carried out. The amount(s) of gas products were determined by an overall mass balance of the experiment using Eq. (3).

$$
\begin{aligned}
& \text { Gas yield (\%) } \\
& =\frac{(\text { mass of LDPE }- \text { mass of liquid }- \text { mass of char })}{\text { mass of LDPE }} \times 100
\end{aligned}
$$

Fig. 1 Process flow diagram for the catalytic cracking of gaseous product of LDPE pyrolysis

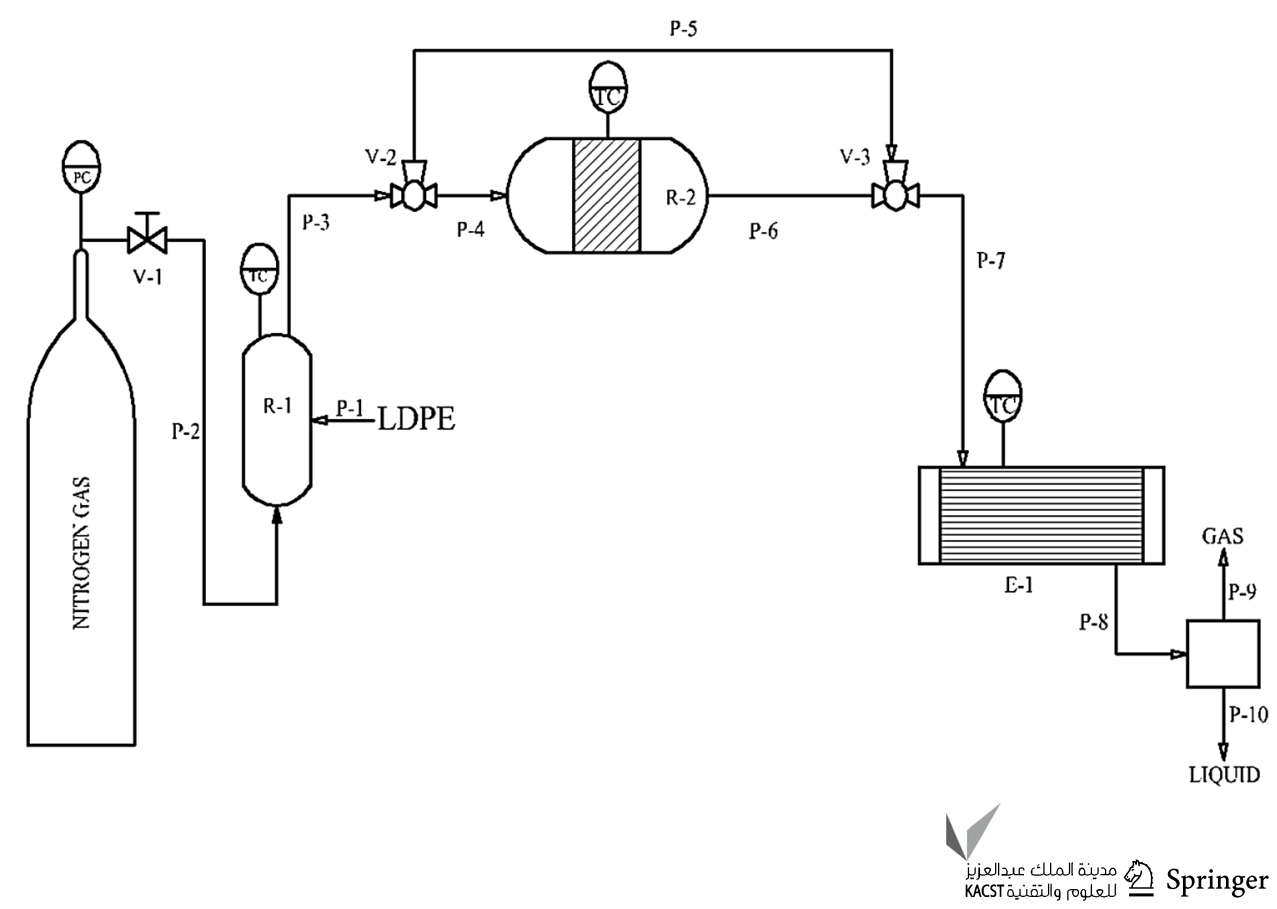




\section{Characterization of the LDPE condensate using FTIR and GC/MS}

The reformed products of the pyrolysed LDPE were condensed and collected using a circulating chiller. The condensate of each sample was analysed using Fourier transform infrared spectroscopy (FTIR). A Shimadzu FTIR-8400S was used to obtain the transmittance at $500-3000 \mathrm{~cm}^{-1}$ range.

The composition of the condensate was analysed using a gas chromatography/mass spectrometry (GC/MS) machine (19091S-433UI Agilent). The column of the GC/MS was equipped with $30 \mathrm{~m} \times 250 \mu \mathrm{m} \times 0.25 \mu \mathrm{m}$ capillary. Helium was used as a carrier gas at $0.75633 \mathrm{ml} / \mathrm{min}$ flowrate. The GC/MS oven was initially held at $45^{\circ} \mathrm{C}$ for $3 \mathrm{~min}$ before being heated to $300{ }^{\circ} \mathrm{C}$ at $10{ }^{\circ} \mathrm{C} / \mathrm{min}$ and held for $20 \mathrm{~min}$. The peaks of the resulting chromatographs were identified using the National Institute of Standards and Technology (NIST) standard reference database. The percentage area of each compound identified was used to represent their relative amount or selectivity.

\section{Results and discussion}

\section{Catalysts characterization}

Figure 2 shows the X-ray diffraction pattern of the FeZSM-5 samples prepared by impregnation method, where A1 is the conventional ZSM-5, A2 is the acid-treated ZSM-5, A3 is $0.3 \mathrm{wt} \%$ iron loading on acid-treated ZSM5 , A4 is $0.6 \mathrm{wt} \%$ iron loading on acid-treated ZSM-5 and A5 is $1 \mathrm{wt} \%$ iron loading on acid-treated ZSM-5. The results show that there were reflection peaks at $2 \theta=7.99^{\circ}$, $9.14^{\circ}, 23.21^{\circ}, 23.64^{\circ}$ and $24.38^{\circ}$, which correspond to the framework structure of ZSM-5 [17]. The sharpness of the peak(s) suggests that all the catalysts are characterized by a good crystallinity. The results indicate that the zeolite structure of ZSM-5 was maintained even after

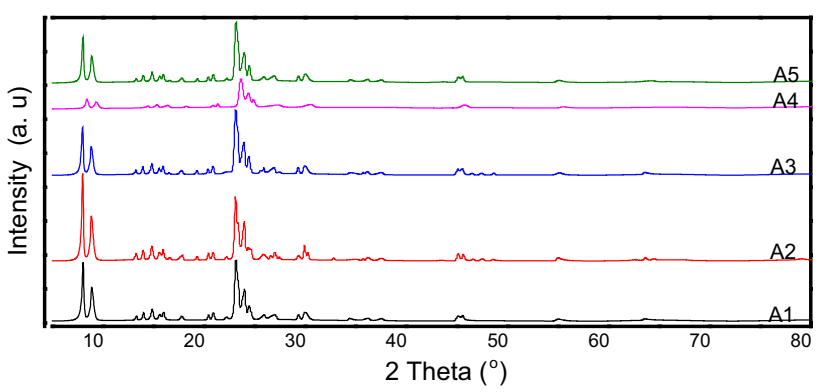

Fig. 2 XRD pattern of ZSM-5 $\mathrm{Si} / \mathrm{Al}=50$ using conventional ZSM-5 (A1), acid-treated ZSM-5 (A2), $0.3 \mathrm{wt} \%$ iron loading on ZSM-5 (A3), $0.6 \mathrm{wt} \%$ iron loading on ZSM-5 (A4) and $1 \mathrm{wt} \%$ iron loading on ZSM-5 (A5) treatment and modification. The typical diffraction lines for iron oxide were not visible in the diffractograms of all the samples. In particular, there are no peaks at $2 \theta$ value(s) of $33.15^{\circ}$ and $35.65^{\circ}$ (which indicate the presence of iron oxide). This lack of XRD peaks for iron oxide may be because of the small amount of iron loaded (maximum $1 \mathrm{wt} \%)$ which was also reported by Aziz et al. [18]. This may be because the loading of the iron is less than $5 \mathrm{wt} \%$ [19]. Thus, the diffraction patterns of the Fe-ZSM-5 samples resemble that of the H-ZSM-5 parent material with no extra peak(s) belonging to the other phases present; this is similar to that reported in the literature [20].

Figure 3 shows FTIR spectra $\left(400-1800 \mathrm{~cm}^{-1}\right)$ of all the catalysts. The figure shows characteristic band at $1220 \mathrm{~cm}^{-1}$, which denotes the T-O-T asymmetric stretching mode (between $\mathrm{TO}_{4}$ tetrahedral), typical of well-crystallized zeolites, and another band at $550 \mathrm{~cm}^{-1}$, which denotes the asymmetric stretching mode of the five-membered rings of the pentasil ZSM-5 zeolite structure [21]. The symmetric stretching vibration of $\mathrm{Si}-\mathrm{O}-\mathrm{Al}$ framework can also be seen at wavenumbers of 450, 550, 1050 and $1200 \mathrm{~cm}^{-1}$. These wavebands increase to higher values for A2 due to the effect of the acid treatment and decrease for $\mathrm{A} 3, \mathrm{~A} 4$ and $\mathrm{A} 5$ as a result of the iron impregnation.

In addition, the stretching vibrations at 1350, 1500, 1600 and $1700 \mathrm{~cm}^{-1}$ indicate the bending vibration of $\mathrm{O}-\mathrm{H}-\mathrm{O}$. The intensities reduce and broaden for A3, A4 and A5, as a result of iron impregnation, while it becomes sharper for A2 (acid-treated ZSM-5), implying pores were opened more. Hence, the metal impregnation inside the inner pores of the catalyst was achieved, as reported in the literature [18]. This shows that there is no structural damage and the ZSM-5 catalysts have their distinct properties. Thus, Figs. 2 and 3 show that the crystallinity of the catalysts as confirmed by both the XRD and FTIR techniques is very high, consequently confirming that the intense conditions employed during the chemical and thermal treatments did not affect the structural characteristics of the catalysts.

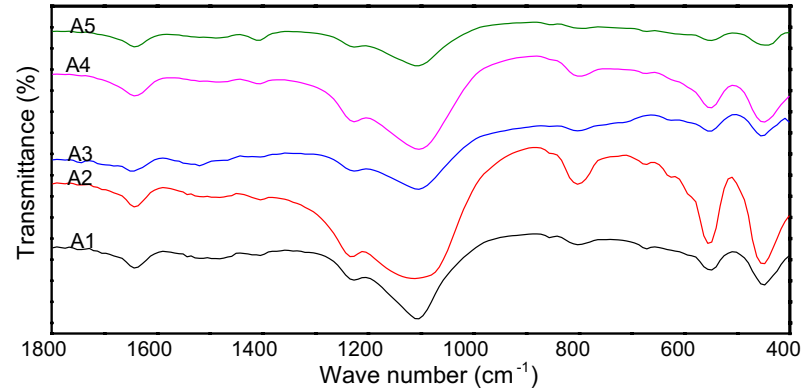

Fig. 3 FTIR spectra of ZSM-5 Si/Al=50 using conventional ZSM-5 (A1), acid-treated ZSM-5 (A2), 0.3 wt \% iron loading on ZSM-5 (A3), $0.6 \mathrm{wt} \%$ iron loading on ZSM-5 (A4) and $1 \mathrm{wt} \%$ iron loading on ZSM-5 (A5) 
Important physicochemical properties of the ZSM-5 and the modified catalysts (Fe-ZSM-5) used in this study are presented in Table 1. The results show that following the initial acid treatment, the surface area of the catalyst increased slightly. This can be attributed to dealumination of zeolite by the acid treatment [22]. When the acid-treated catalysts were then impregnated with iron, the surface area decreased significantly. However, subsequent increase in the iron loading resulted in the increase in the surface area. It is likely that the iron was deposited more on the external surface area as in sample A5 and in the internal surface area in sample A3 and A4. Hence, BET surface area and the Langmuir surface area show that A5, which represents the highest (1 wt \%) iron loading on ZSM-5, has the highest surface area compared to the other catalysts, including the conventional ZSM-5 zeolite. Table 1 also shows that the micropore volumes of the modified catalysts A4 and A5 were significantly lower compared to that of the conventional ZSM-5 zeolite, while those of A2 and A3 were higher. The results correspond with the expectation of an increase in pore volume due to acid treatment and also due to the decrease in iron loading [18]. The FTIR result in Fig. 3 also shows that Fe was deposited more inside the pores of the catalyst. Nevertheless, the micropore volume(s) and the average pore size(s) of all of the samples (A1-A5) are within the range of the standard values (less than $2 \mathrm{~nm}$ ) [23]. The crystallite sizes of the catalysts, which were obtained using the Debye-Scherrer method, were determined to be in the range of 17.13-23.51 nm.

The scanning electron microscope (SEM) images of conventional zeolites, before and after the acid treatment, are shown in Fig. 4. It can be observed that conventional zeolite has an irregular morphology and a thin plate-like structural pattern (lamellar). After the $\mathrm{HCl}$ treatment, there was dealumination of the ZSM-5 structure in $\mathrm{A} 2$ as reported in the literature [24]. A3, A4 and A5 show structural morphological growth, indicating the presence of $\mathrm{Fe}$, which is consistent with the previous results.

\section{Effect of temperature and catalyst type on the reforming of gaseous products of LDPE pyrolysis}

The LDPE pyrolysis in the pyrolyser produced negligible char yield of about $2 \mathrm{wt} \%$, suggesting that LDPE was almost completely decomposed to volatile compounds. These volatile compounds served as feed to the catalytic bed reformer. Figure 5 shows the material balance of product yields of liquid and gas of the reformed LDPE, around the catalytic bed. Figure $5 \mathrm{a}-\mathrm{c}$ shows that as the temperature increases from 400,450 to $500{ }^{\circ} \mathrm{C}$, the non-condensable gas increases, to the detriment of the condensates
Table 1 Physicochemical properties of conventional ZSM-5 (A1), acid-treated ZSM-5 (A2), 0.3 wt\% iron loading on ZSM-5 (A3), $0.6 \mathrm{wt} \%$ iron loading on ZSM-5 (A4) and $1 \mathrm{wt} \%$ iron loading on ZSM-5 (A5)

\begin{tabular}{llllll}
\hline Sample & $\begin{array}{l}\text { BET surface area } \\
\left(\mathrm{m}^{2} / \mathrm{g}\right)\end{array}$ & $\begin{array}{l}\text { Langmuir surface } \\
\text { area }\left(\mathrm{m}^{2} / \mathrm{g}\right)\end{array}$ & $\begin{array}{l}\text { Micropore volume } \\
\left(\mathrm{cm}^{3} / \mathrm{g}\right)\end{array}$ & $\begin{array}{l}\text { Average pore } \\
\text { size }(\mathrm{nm})\end{array}$ & $\begin{array}{l}\text { Crystallite } \\
\text { size }(\mathrm{nm})\end{array}$ \\
\hline $\mathrm{A} 1$ & 343 & 460 & 0.1655 & 1.9326 & 23.51 \\
$\mathrm{~A} 2$ & 348 & 467 & 0.1724 & 1.9810 & 23.41 \\
$\mathrm{~A} 3$ & 153 & 208 & 0.1875 & 1.9643 & 23.13 \\
$\mathrm{~A} 4$ & 248 & 327 & 0.1121 & 1.8106 & 17.13 \\
$\mathrm{~A} 5$ & 392 & 519 & 0.0750 & 1.9151 & 22.80 \\
\hline
\end{tabular}
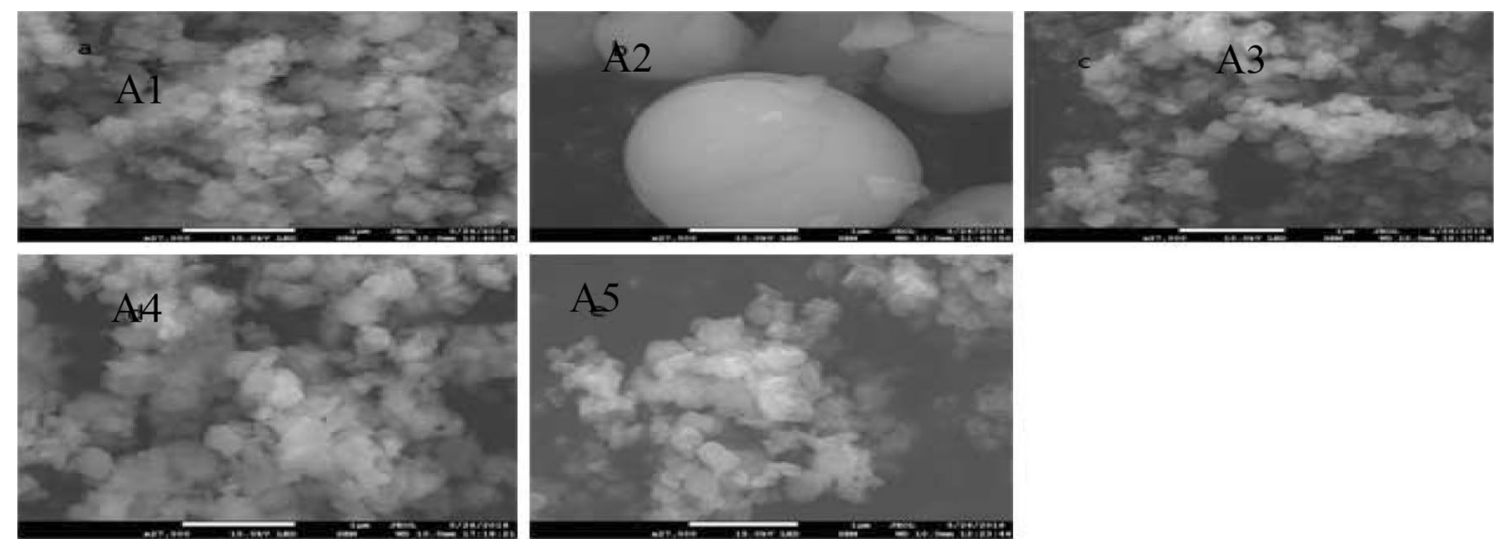

Fig. 4 SEM images ( $\times 27,000$ magnification) of ZSM-5 Si/Al=50 using conventional ZSM-5 (A1), acid-treated ZSM-5 (A2), 0.3 wt\% iron loading on ZSM-5 (A3), $0.6 \mathrm{wt} \%$ iron loading on ZSM-5 (A4) and $1 \mathrm{wt} \%$ iron loading on ZSM-5 (A5) 
(liquid fuel), in both the thermal and catalytic pyrolyses. For example, in the thermal pyrolysis (Blank run), there is an increase in the non-condensable gas production from 31 to $43 \mathrm{wt} \%$, while the condensates decreased from 69 to $57 \mathrm{wt} \%$ when the temperature increased $\left(400-500{ }^{\circ} \mathrm{C}\right)$. Study has shown that as temperature increases, the cracking of the longer-chain hydrocarbon also increases [21]. Therefore, in thermal pyrolysis, the increase in temperature increases the volume of non-condensable gas and reduces the volume of the liquid fraction.

A similar trend of the decrease in liquid fraction yield and the increase in the non-condensable gas in the blank run was also noted across all the catalysts studied (Fig. 5). This pattern was more conspicuous with A5 catalyst ( $1 \mathrm{wt} \%$ iron loading on ZSM-5) where the non-condensable gas production increased from 31 to $58 \mathrm{wt} \%$, while that of the liquid fraction decreased from 69 to $42 \mathrm{wt} \%$. The physicochemical result presented earlier (Table 1) shows that A5 has the highest BET surface area which probably implies more active sites are available that support the cracking/reforming of heavy hydrocarbons. This opinion is supported in the literature, which suggests that catalyst with high surface area will have more active sites and this will increase the cracking ability of the catalyst [1]. Thus, more gas will be produced.
To get better hindsight on the liquid fractions generated during reforming, Fig. $6 \mathrm{a}-\mathrm{c}$ represents the FTIR spectrum of the LDPE liquid fraction, showing characteristic band range from 500 to $3700 \mathrm{~cm}^{-1}$. Table 2 shows the functional groups and their respective peaks in the FTIR spectrum. Generally, the typical compositions of reformed pyrolysed LDPE condensates have been categorized into groups of paraffin, olefins and aromatic compositions.

The peaks at the 2850-2941, 3000-2700, 1470, 1033 and $721 \mathrm{~cm}^{-1}$ wavelengths represent the chemical functional groups of $-\mathrm{CH}_{2}-$ stretching, $-\mathrm{CH}_{2}-,-\mathrm{CH}$ bending, $-\mathrm{CH}_{2}-$ bending vibration and $-\mathrm{CH}_{2}-$ rocking vibration of the aliphatic hydrocarbon, respectively. The presence of these peaks confirmed the presence of alkanes in the liquid fraction. The presence of $=\mathrm{C}-\mathrm{H}$ out-of-plane bending, $=\mathrm{C}-\mathrm{H}$ inplane bending and $\mathrm{C}=\mathrm{C}$ stretching at wavebands $1000-600$, 1400 and $1680-1600 \mathrm{~cm}^{-1}$, respectively, confirms the presence of alkenes. Likewise the presence of $\mathrm{C}-\mathrm{H}$ stretching, overtone and combination bands, $\mathrm{C}=\mathrm{C}$ stretching, in-plane $\mathrm{C}-\mathrm{H}$ bending and out-of-plane $\mathrm{C}-\mathrm{H}$ bending at 3300-3000, 2000-1700, 1600-1460, 1275-1000 and 900-690 $\mathrm{cm}^{-1}$ wavebands in that order indicates that aromatic groups were also present.
Fig. 5 Product yields of the reformed pyrolysed LDPE using conventional ZSM-5 (A1), acidtreated ZSM-5 (A2), $0.3 \mathrm{wt} \%$ iron loading on ZSM-5 (A3), $0.6 \mathrm{wt} \%$ iron loading on ZSM-5 (A4) and $1 \mathrm{wt} \%$ iron loading on ZSM-5 (A5) catalysts at $400{ }^{\circ} \mathrm{C}$ (a), $450{ }^{\circ} \mathrm{C}(\mathbf{b})$ and $500{ }^{\circ} \mathrm{C}(\mathbf{c})$

\section{(a)}

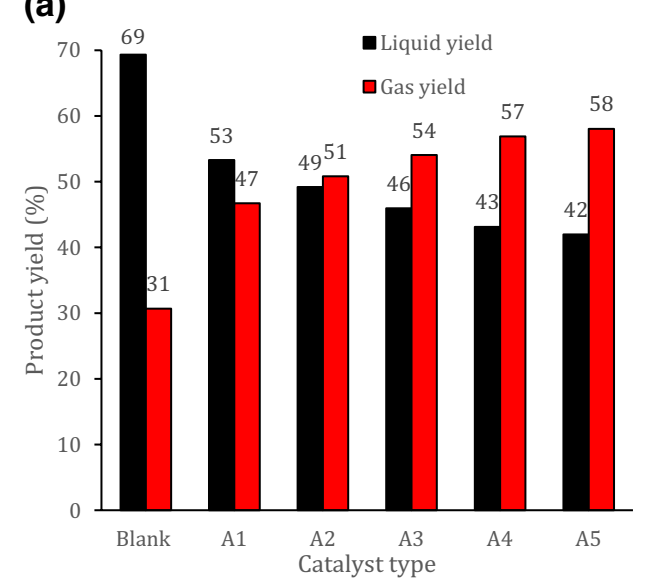

(c)

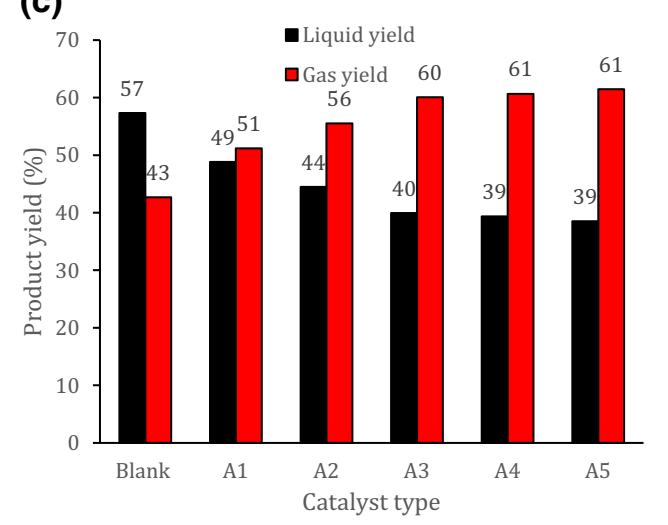

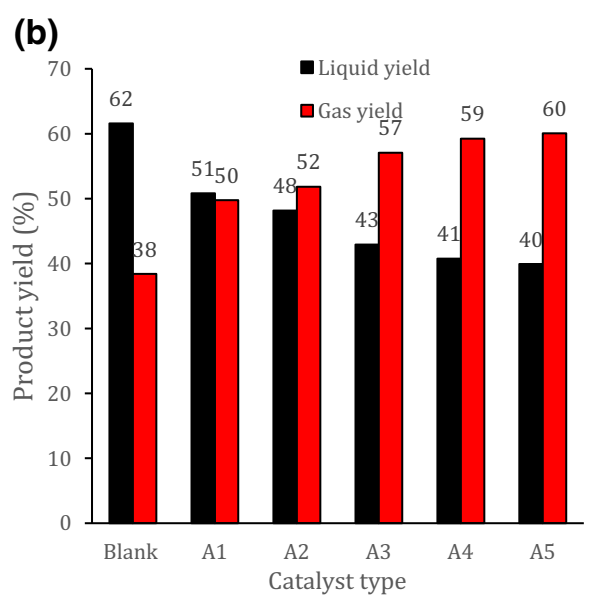




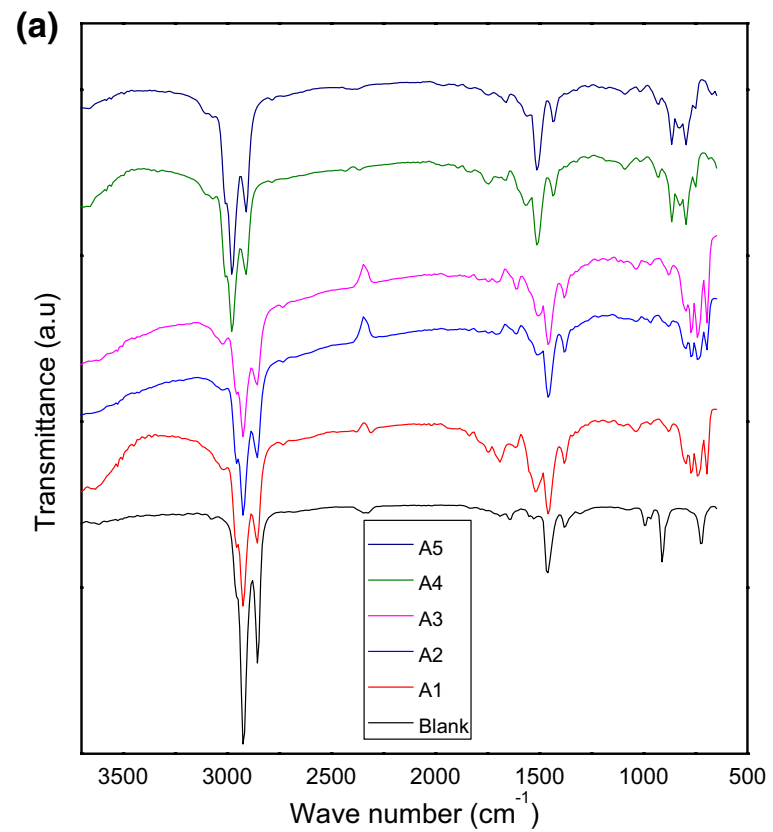

(c)

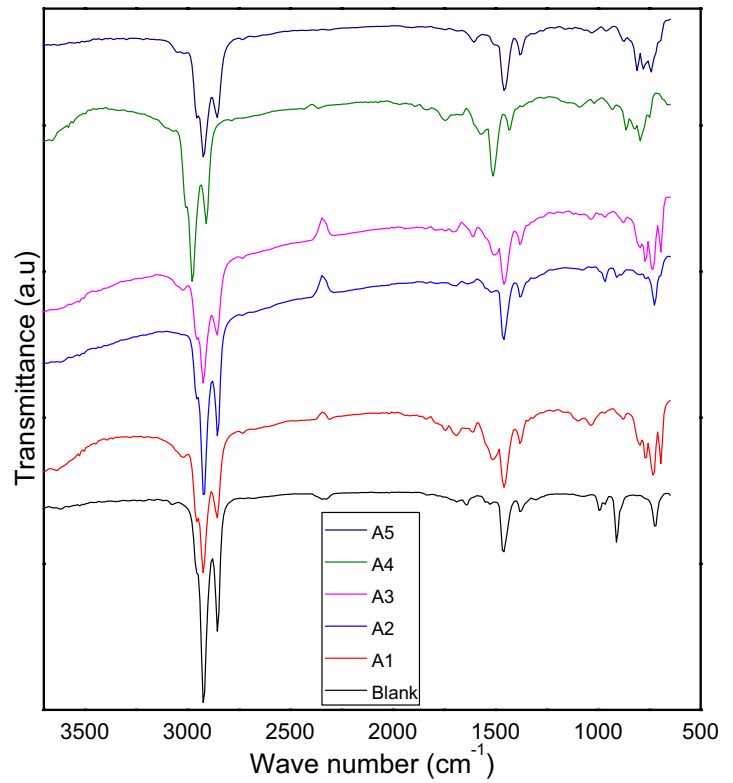

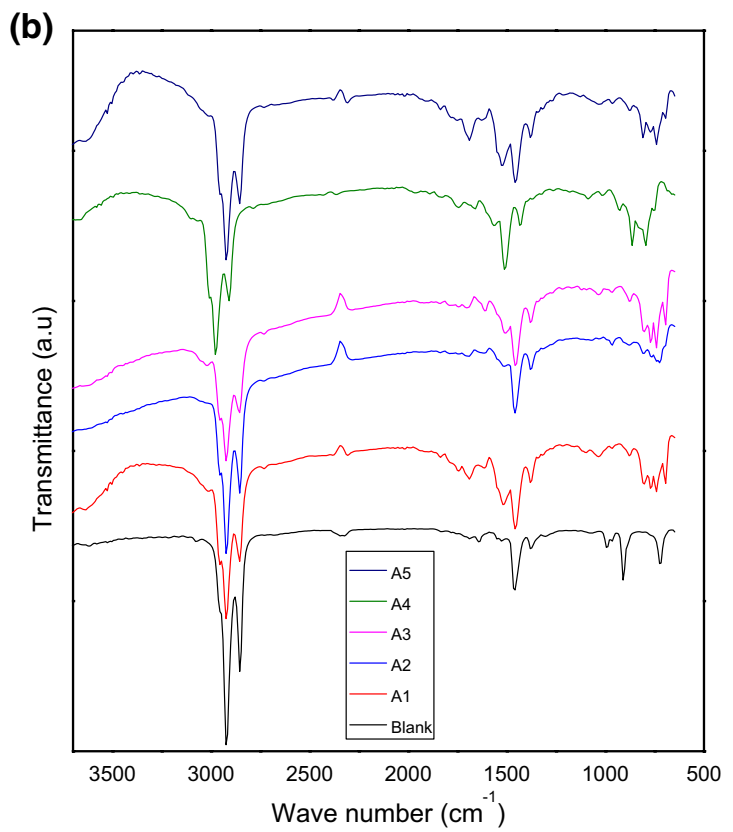

Fig. 6 FTIR spectra of the reformed pyrolysed LDPE condensates using conventional ZSM-5 (A1), acid-treated ZSM-5 (A2), 0.3 wt\% iron loading on ZSM-5 (A3), $0.6 \mathrm{wt} \%$ iron loading on ZSM-5 (A4)

Despite the fact that the catalyst reduced the quantity of the liquid fraction, the FTIR results indicate that the resulting condensates were of higher quality. As catalyst temperature increases, the cracking ability of the catalyst also increases. Longer-chain hydrocarbons $(\mathrm{C}-\mathrm{C})$ are cracked easily to produce shorter-chain hydrocarbon. This alters the amount of non-condensable gases and the condensates produced [25]. and $1 \mathrm{wt} \%$ iron loading on ZSM-5 (A5) catalysts at $400{ }^{\circ} \mathrm{C}$ (a), $450{ }^{\circ} \mathrm{C}(\mathbf{b})$ and at $500{ }^{\circ} \mathrm{C}(\mathbf{c})$

Figure 6 shows an increase in the aromatics (transmittance at the wavenumbers 3300-3000, 2000-1700, 1600-1460 1275-1000 and 900-690 $\mathrm{cm}^{-1}$ ) when catalytic temperature was increased. The increment in the aromatics is quite significant when catalysts were applied and also when iron loading was increased $(0.3,0.6$ and $1 \mathrm{wt} \%)$. Figure 6 shows a decrease in the aliphatic (transmittance at the wavenumbers 2850-2941, 3000-2700, 1470, 1033 and $721 \mathrm{~cm}^{-1}$ ) with the application of the catalysts, as well as when the 
Table 2 Wavebands, type of vibration and functional group associated with condensates using FTIR spectra (3700$500 \mathrm{~cm}^{-1}$ )

\begin{tabular}{llll}
\hline S. no. & Wavebands $\left(\mathrm{cm}^{-1}\right)$ & Type of vibration & Associated functional group \\
\hline 1 & $3300-3000$ & C-H stretching & Aromatics \\
2 & $2000-1700$ & Overtone and combination bands & Aromatics \\
3 & $1600-1460$ & $\mathrm{C}=\mathrm{C}$ stretching & Aromatics \\
4 & $1275-1000$ & In-plane C-H bending & Aromatics \\
5 & $900-690$ & Out-of-plane C-H bending & Aromatics \\
6 & $3100-3000$ & $=\mathrm{C}-\mathrm{H}$ stretching & Alkene \\
7 & $1680-1600$ & $\mathrm{C}=\mathrm{C}$ stretching & Alkene \\
8 & 1400 & $=\mathrm{C}-\mathrm{H}$ in-plane bending & Alkene \\
9 & $1000-600$ & $=\mathrm{C}-\mathrm{H}$ out-of-plane bending & Alkene \\
10 & $3130-3050$ & $\mathrm{C}-\mathrm{H}$ stretching & Alkane \\
11 & $3000-2700$ & $-\mathrm{CH}-$ stretching & Alkane \\
12 & 2924.18 & $\mathrm{C}-\mathrm{H}_{2}$ stretching & Alkane, aliphatic \\
13 & 2854.74 & $\mathrm{C}-\mathrm{H}_{\text {stretching }}$ & Alkane, aliphatic \\
14 & $2850-2941$ & $-\mathrm{CH}_{2}-$ stretching & Alkane \\
15 & 1470 & $-\mathrm{CH}-$ bending vibration & Alkane \\
16 & 1033.88 & $\mathrm{C}-\mathrm{H}$ bending & Alkane \\
17 & 721 & $-\mathrm{CH}-$ rocking vibration & Alkane \\
18 & $1700-1590$ & $\mathrm{C}=\mathrm{C}$ stretching & Alkyne \\
19 & 990 & Vinyl double-bond stretching & Ethenyl \\
20 & 960 & Terminal olefins/alkene stretching & Ethane \\
21 & 950 & Terminal olefins/alkene stretching & Ethane \\
\hline
\end{tabular}

iron loading was increased. The same trend is observed when catalyst temperature was increased $\left(400-500{ }^{\circ} \mathrm{C}\right)$. Therefore, the application of the Fe-ZSM-5 catalysts and increasing the temperature increase cracking/fragmentation, recombination/oligomerization, isomerization, cyclization and dehydrogenation of the process. The literature suggests that Lewis acid sites of the catalyst are responsible for the cracking, while the Brönsted acid site is responsible for the aromatization [11]. Fe-ZSM-5 catalyst is a microporous zeolite catalyst that favours dehydrogenation process [9]. The Fe-ZSM- 5 catalyst increases the amount of non-condensable gas and decreases the amount of condensate, but with higher percentage of aromatics (Fig. 6). Thus, the hydrocarbons produced when the catalysts are used contain low-carbon chain compounds (gasoline range) in comparison with the thermal pyrolysis.

The increase in catalyst temperature $\left(400-500{ }^{\circ} \mathrm{C}\right)$ also enhances aromatization processes. The aliphatic hydrocarbon will be converted into aromatic hydrocarbons, undergoing catalytic (Fe-ZSM-5) cracking (Figs. 5, 6). Temperature of the catalyst affects both the quantity and type of the aromatic being formed. High catalyst temperature favours cracking and aromatizing reactions of both mono- and double rings [9]. In particular, low catalytic temperature produces mostly the single-ring aromatics, while the high temperature increases the double-ring hydrocarbon [25].

In this study, reforming of pyrolysed LDPE condensates using the catalyst $\mathrm{A} 5$ at $450{ }^{\circ} \mathrm{C}$ gave the highest amount of aromatic composition (Fig. 6b), while $\mathrm{A} 5$ at $500{ }^{\circ} \mathrm{C}$ gave the highest amount of non-condensable gas (Fig. 5c). Thus, $450{ }^{\circ} \mathrm{C}$ is the optimum temperature for the aromatic production using Fe-ZSM-5 catalyst.

\section{Effect of catalysts loading on reforming of gaseous products of LDPE}

Based on the selectivity towards aromatics, A5 with $1 \mathrm{wt} \%$ iron on ZSM-5 at $450{ }^{\circ} \mathrm{C}$ was selected for the effect of

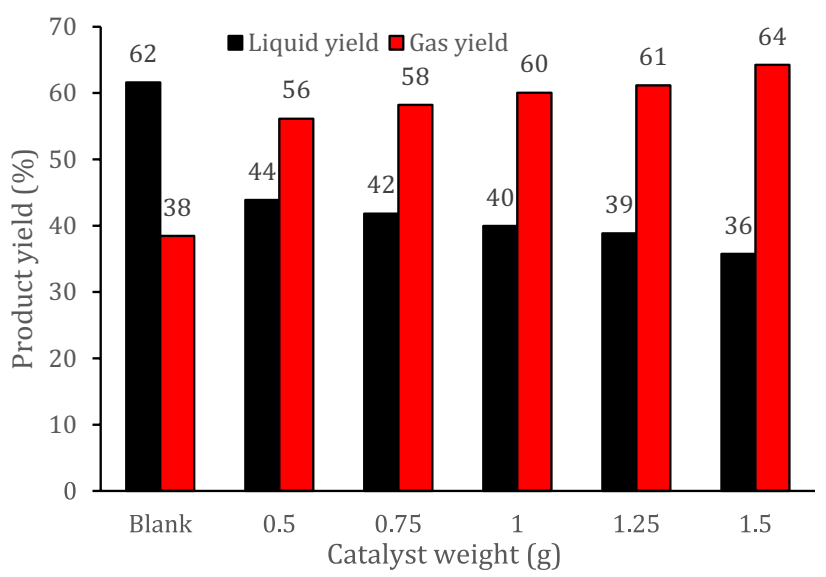

Fig. 7 Product yields of the reformed pyrolysed LDPE using $1 \mathrm{wt} \%$ iron loading on ZSM-5 (A5) catalysts at $450{ }^{\circ} \mathrm{C}$ and at different catalyst loadings 


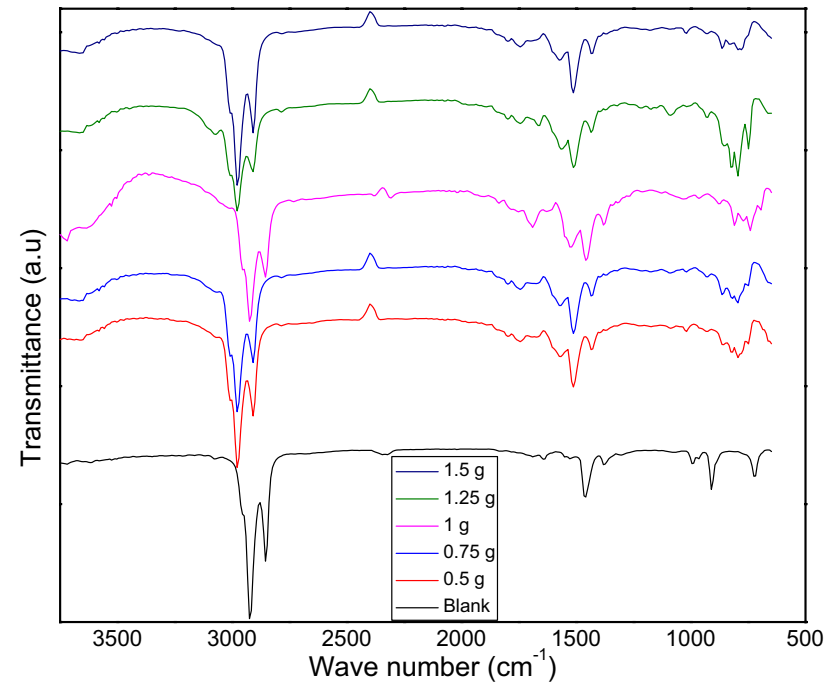

Fig. 8 FTIR spectra of the reformed pyrolysed LDPE condensates using $1 \mathrm{wt} \%$ iron loading on ZSM-5 (A5) catalysts at $450{ }^{\circ} \mathrm{C}$ and at different loadings

catalyst loading study. Figures 7 and 8 show the effect of catalyst loading $(0.5,0.75,1,1.25$ and $1.5 \mathrm{~g})$ on the LDPE pyrolysis.

The increase in the catalyst loading $(0.5,0.75,1,1.25$ and $1.5 \mathrm{~g}$ ) increases the amount of the non-condensable gas (Fig. 7) but decreases the liquid fraction yield. However, the amount of the aromatics in the liquid fraction was enhanced when the catalyst loading was increased (Fig. 8: 3300-3000, 1275-1000 and 900-690 $\mathrm{cm}^{-1}$ ). Thus, the increase in the catalyst loading does not only increase the production of non-condensable of gas, but also improve the quality of the condensates. The catalyst plays a vital role in improving the quality of the condensate.

\section{Compositional analysis of the reformed condensate of the pyrolysed LDPE}

The compositional analysis of the reformed pyrolysed LDPE condensates was done using GC-MS to confirm the FTIR results via identification of the specific hydrocarbons. Figure 9 shows the chromatographs of the blank (without catalyst), 1 and $1.25 \mathrm{~g}$ of $1 \mathrm{wt} \% \mathrm{Fe}$ on ZSM-5 catalysts at $450{ }^{\circ} \mathrm{C}$. Table 3 gives the summary of the most abundant components in the condensates, retention time, relative area and the hydrocarbon types based on the $\mathrm{GC} /$ MS results. The peaks of chromatographs were identified using NIST standard reference database.

The blank run in Fig. 9 shows a wide range of identified hydrocarbons, while 1 and $1.25 \mathrm{~g}$ of $1 \mathrm{wt} \% \mathrm{Fe}$ on ZSM-5 catalysts contain smaller range of the hydrocarbons. Table 3 shows that most of the hydrocarbons identified in the blank run were aliphatic. The aliphatic includes nonadecane, tetradecene, hexadecane, pentadecane and octadecane. It also shows that the 1 and $1.25 \mathrm{~g}$ loading of the catalyst A5 contained small range of aromatics. This indicates that most of the aliphatic hydrocarbons in the blank run were converted to aromatic when the Fe-ZSM-5 catalysts were used. Thus, Fe-ZSM-5 is selective towards aromatics in the reforming of the pyrolysed LDPE. The

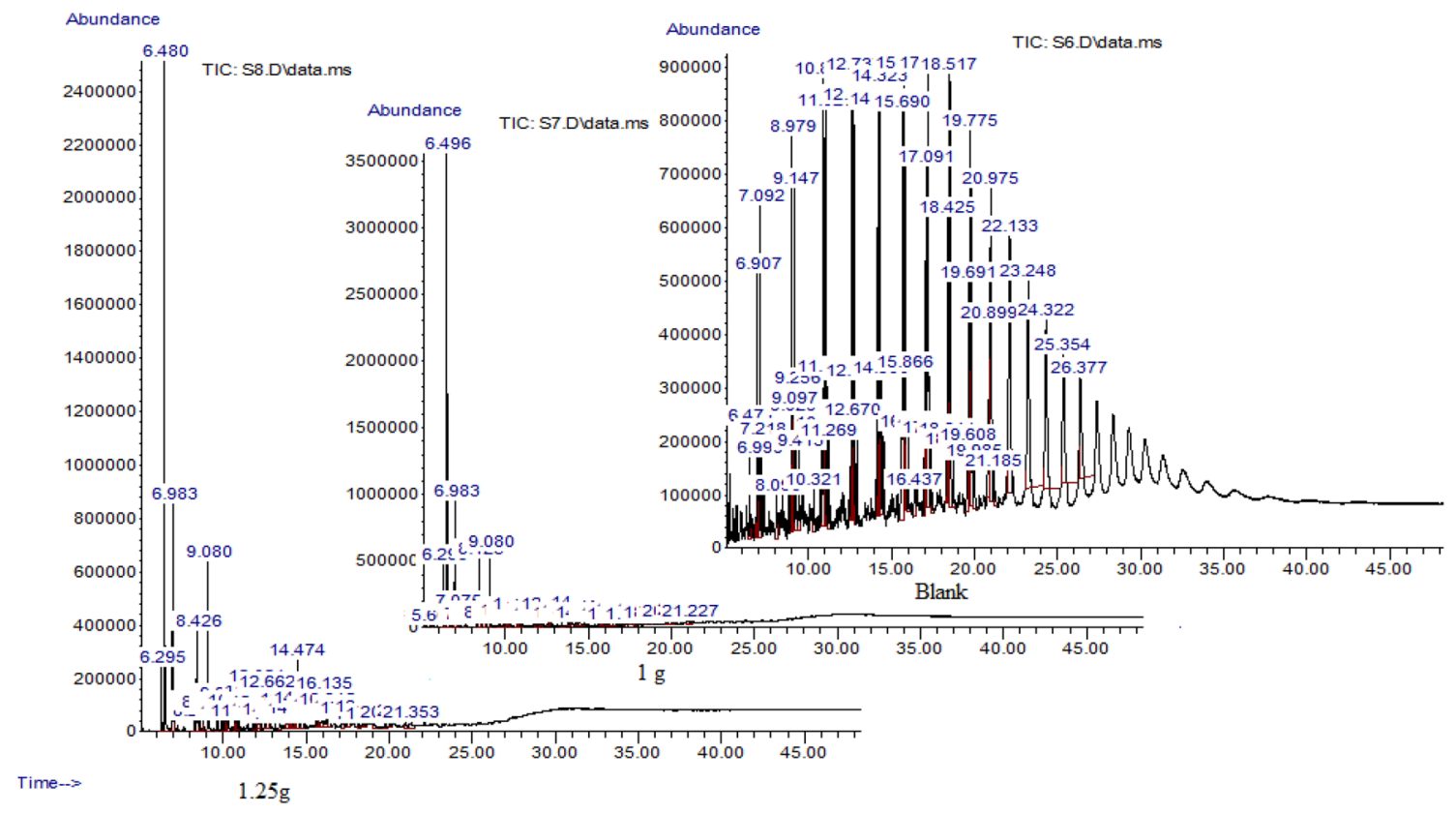

Fig. 9 Chemical composition of the condensates from GC/MS analysis for blank (no catalyst), $1 \mathrm{~g}$ and $1.25 \mathrm{~g}$ Fe-ZSM-5 of $1 \mathrm{wt} \%$ iron loading (A5) catalysts at $450{ }^{\circ} \mathrm{C}$ 
Table 3 Most abundant component of the reformed pyrolysed condensates of LDPE at $450{ }^{\circ} \mathrm{C}$, based on GC/MS results

\begin{tabular}{|c|c|c|c|c|c|}
\hline Catalyst & Name of the hydrocarbon & Retention time & Relative area & Types & Structures \\
\hline \multirow[t]{11}{*}{ Blank run } & Nonadecane & 22.13 & 5.86 & Aliphatic & $\triangle \wedge$ \\
\hline & Tetradecene & 15.69 & 5.24 & Olefins & \\
\hline & Hexadecane & 18.517 & 4.94 & Aliphatic & \\
\hline & Pentadecane & 17.20 & 4.9 & Aliphatic & \\
\hline & Octadecane & 20.98 & 4.73 & Aliphatic & \\
\hline & 1-Undecene & 10.88 & 3.55 & Olefins & \\
\hline & 1-Pentadecene & 17.09 & 3.55 & Olefins & \\
\hline & 1-Tridecene & 14.20 & 3.46 & Olefins & \\
\hline & Tetradecane & 15.80 & 3.36 & Aliphatic & \\
\hline & Heptadecane & 19.78 & 4.88 & Aliphatic & \\
\hline & P-Xylene & 6.50 & 0.90 & Aromatics & \\
\hline \multirow[t]{11}{*}{ A5 (1 g) } & P-Xylene & 6.50 & 40.69 & Aromatics & \\
\hline & O-Xylene & 6.98 & 9.14 & Aromatics & \\
\hline & 1-Ethyl-3-methyl-benzene & 8.43 & 7.98 & Aromatics & \\
\hline & 1.2,3-Trimethyl-benzene & 9.08 & 7.69 & Aromatics & \\
\hline & Ethylbenzene & 6.30 & 4.8 & Aromatics & \\
\hline & 2-Methyl-Naphthalene & 14.47 & 2.36 & Aromatics & \\
\hline & 2,3-Dihydro-5-methyl-1H-indene & 11.83 & 1.22 & & \\
\hline & 1-Methyl-1H-indene & 12.02 & 1.11 & & \\
\hline & 2,6-Dimethyl-naphthalene & 16.14 & 1.31 & Aromatics & \\
\hline & 2,6-Dimethyl-naphthalene & 16.34 & 1.22 & Aromatics & \\
\hline & Heptadecane & 19.76 & 0.78 & Aliphatic & \\
\hline \multirow[t]{3}{*}{ A5 $(1.25 \mathrm{~g})$} & P-Xylene & 6.48 & 27.23 & Aromatics & \\
\hline & O-Xylene & 6.98 & 9.36 & Aromatics & \\
\hline & 1,2,3-Trimethyl-benzene & 9.08 & 8.11 & Aromatics & \\
\hline
\end{tabular}


Table 3 (continued)

\begin{tabular}{|c|c|c|c|c|c|}
\hline Catalyst & Name of the hydrocarbon & Retention time & Relative area & Types & Structures \\
\hline & 1-Ethyl-3-methyl-benzene & 8.43 & 6.05 & Aromatics & \\
\hline & 2-Methyl-naphthalene & 14.47 & 4.69 & Aromatics & \\
\hline & Naphthalene & 12.66 & 2.99 & Aromatics & \\
\hline & 2,6-Dimethyl-naphthalene & 16.35 & 2.69 & Aromatics & \\
\hline & 1,6-Dimethyl-naphthalene & 16.14 & 2.63 & Aromatics & \\
\hline & 1-Ethenyl-4-ethylbenzene & 11.83 & 1.81 & Aromatics & \\
\hline & 1,3-Dimethyl-benzene & 6.3 & 2.68 & Aromatics & \\
\hline & Heptadecane & 19.76 & 0.65 & Aliphatic & \\
\hline
\end{tabular}

$1 \mathrm{~g}$ and $1.25 \mathrm{~g}$ of catalyst A5 contained predominantly p-xylene aromatics. However, the $1 \mathrm{~g}$ of catalyst A5 contained some amounts of aromatics, which are single-ring aromatics (P-xylene, 1,2,3-trimethyl-benzene, ethylbenzene, etc.), while the $1.25 \mathrm{~g}$ of catalyst contain some aromatics, which are double-ring aromatics (naphthalene, 2-methyl-naphthalene, 2,6-dimethyl-naphthalene, etc.). This is because more active sites are available in $1.25 \mathrm{~g}$ than in $1 \mathrm{~g}$ of A5 catalyst.

The GC/MS results show that the aromatic hydrocarbon composition increased relatively to about $70 \%$ of the reformed condensates when Fe-ZSM-5 was used. The condition for the best catalytic condensates (i.e. high percentage of aromatics) was found to be at catalytic temperature of $450{ }^{\circ} \mathrm{C}$ and at $1.25 \mathrm{~g}$ of catalyst weight of $\mathrm{A} 5$, while the maximum gas yield was obtained at $500{ }^{\circ} \mathrm{C}$ and at $1 \mathrm{~g}$ of catalyst.

\section{Conclusions}

The Fe-ZSM-5 catalysts produced for LDPE reforming were found to be structurally stable despite treatment as confirmed from the XRD, FTIR, BET and SEM characterizations. The increase in the reformer temperature increases the volume of non-condensable gas and reduces the volume of the liquid fraction in both the thermal and catalytic pyrolyses. However, the trend was at higher level for the catalytic pyrolysis. The same trend was also observed for the catalyst types and across the increase in the catalysts loadings. The liquid fraction of the thermal pyrolysis was found to be composed of aliphatic, while catalytic thermal pyrolysis was aromatics. The iron loading on ZSM-5 was found to enhance the generation of aromatics during catalytic thermal pyrolysis.

Open Access This article is distributed under the terms of the Creative Commons Attribution 4.0 International License (http://creativeco mmons.org/licenses/by/4.0/), which permits unrestricted use, distribution, and reproduction in any medium, provided you give appropriate credit to the original author(s) and the source, provide a link to the Creative Commons license, and indicate if changes were made.

\section{References}

1. Renzini MS, Sedran U, Pierella LB (2009) H-ZSM-11 and ZnZSM-11 zeolites and their applications in the catalytic transformation of LDPE. J Anal Appl Pyrolysis 86(1):215-220

2. Gbolahan I, Folorunsho H, Umaru A (2018) Catalytic pyrolysis of waste polypropylene using Ahoko kaolin from Nigeria. Appl Petrochem Res 8:203-210

3. Hamidi N, Tebyanian F, Massoudi R, Whitesides L (2013) Pyrolysis of household plastic wastes. Br J Appl Sci Technol 3(3):417-439

4. Sethi B (2016) Recycling of polymers in the presence of nanocatalysts: a green approach towards sustainable environment. Int J Environ Ecol Eng 10(5):472-478 
5. Gumula T, Paluszkiewicz C, Blazewicz S (2009) Study on thermal decomposition processes of polysiloxane polymers-From polymer to nanosized silicon carbide. J Anal Appl Pyrolysis 86(2):375-380

6. Sarker M, Rashid MM, Rahman S, Molla M (2012) Conversion of low density polyethylene (LDPE) and polypropylene (PP) waste plastics into liquid fuel using thermal cracking process. Br J Environ Clim Change 2(1):1-11

7. Sarker M, Mamunor Rashid M, Molla M (2012) First waste plastic conversion into liquid fuel by using muffle furnace through reactor. Int J Energy Eng 2(6):293-303

8. Sonawane YB, Shindikar M, Khaladkar M (2015) Use of catalyst in pyrolysis of polypropylene waste into liquid fuel. Int Res J Environ Sci 4(7):24-28

9. Kumar S, Panda AK, Singh RK (2011) A review on tertiary recycling of high-density polyethylene to fuel. Resour Conserv Recycl 55(11):893-910

10. Seo YH, Lee KH, Shin DH (2003) Investigation of catalytic degradation of high-density polyethylene by hydrocarbon group type analysis. J Anal Appl Pyrolysis 70(2):383-398

11. Renzini MS, Sedran U, Pierella LB (2009) H-ZSM-11 and ZnZSM-11 zeolites and their applications in the catalytic transformation of LDPE. J Anal Appl Pyrolysis 86(1):215-220

12. Nishino J, Itoh M, Fujiyoshi H, Uemichi Y (2008) Catalytic degradation of plastic waste into petrochemicals using Ga-ZSM-5. Fuel 87(17-18):3681-3686

13. Zhang Y, Huang J, Williams PT (2017) Fe-Ni-MCM-41 catalysts for hydrogen-rich syngas production from waste plastics by pyrolysis-catalytic steam reforming. Energy Fuels 31(8):8497-8504

14. Sun K, Xia H, Hensen E, Van Santen R, Li C (2006) Chemistry of N2O decomposition on active sites with different nature: effect of high-temperature treatment of Fe/ZSM-5. J Catal 238:186-195

15. Jaroniec M, Kruk M, Sayari A (2000) Recent advances in adsorption characterization of mesoporous molecular sieves. Stud Surf Sci Catal 129:587-596

16. Saito A, Foley HC (1991) Curvature and parametric sensitivity in models for adsorption in micropores. AIChE J 37(3):429-436

17. Khoshbin R, Karimzadeh R (2017) The beneficial use of ultrasound in free template synthesis of nanostructured ZSM-5 zeolite from rice husk ash used in catalytic cracking of light naphtha: effect of irradiation power. Adv Powder Technol 28:973-982

18. Aziz A, Kim S, Kim KS (2016) Fe/ZSM-5 zeolites for organicpollutant removal in the gas phase: effect of the iron source and loading. J Environ Chem Eng 4(3):3033-3040

19. Calsavara V, Luciano M (2008) Transformation of ethanol into hydrocarbons on ZSM-5 zeolites modified with iron in different ways. Fuel 87:1628-1636

20. Zhao T, Zhang H, Li F, Yang C, Zong B (2005) Synthesis and characterization of ZSM-5/ $\beta$ co-crystalline zeolite. J Nat Gas Chem 14:95-100

21. Figueiredo AL et al (2016) Catalytic cracking of LDPE over nanocrystalline HZSM-5 zeolite prepared by seed-assisted synthesis from an organic-template-free system. J Anal Appl Pyrolysis 117:132-140

22. Iliopoulou EF et al (2014) Pilot-scale validation of Co-ZSM-5 catalyst performance in the catalytic upgrading of biomass pyrolysis vapours. Green Chem 16(2):662-674

23. Agullo $\mathrm{J}$ et al (2007) Catalytic pyrolysis of low density polyethylene over H- $\beta, \mathrm{H}-\mathrm{Y}, \mathrm{H}-\mathrm{Mordenite}$, and H-Ferrierite zeolite catalysts: influence of acidity and structures. Kinet Catal 48(4):535-540

24. Syamsiro M, Cheng S, Hu W, Saptoadi H, Syamsiro M (2015) Liquid and gaseous fuel from waste plastics by sequential pyrolysis and catalytic reforming processes over Indonesian natural zeolite catalysts fulltext refbacks. Waste Technol 2:1-3

25. Miandad R, Barakat MA, Aburiazaiza AS, Rehan M, Nizami AS (2016) Catalytic pyrolysis of plastic waste: a review. Process Saf Environ Prot 102:822-838

Publisher's Note Springer Nature remains neutral with regard to jurisdictional claims in published maps and institutional affiliations. 